\title{
Alfabetização em Informação e a Capacitação do Agente Comunitário de Saúde: Proposta de mediação baseada no Modelo Extensivo e Colaborativo (Todos-Todos)
}

\author{
Elmira Simeão \\ Doutora em Ciência da Informação. Professora da Universidade de Brasília. \\ elmira@unb.br \\ Cristiano Melo \\ Mestre em Ciência da Informação. \\ cristiano_melo@msn.com
}

Resumo: Há uma literatura emergente na Ciência da Informação que trata dos mecanismos e processos de alfabetização em informação (information literacy), ou ALFIN, sigla que é divulgada pela UNESCO e que foi já foi adotada pela comunidade científica que estuda o assunto. Nesse artigo, apresenta-se uma metodologia amparada no modelo de comunicação extensiva (Simeão, 2005) para trazer novos horizontes para ALFIN numa pesquisa aplicada ao contexto da comunicação da informação em saúde no Brasil. O trabalho avalia a mediação dos Agentes Comunitários de Saúde em sua atuação no Sistema Único de Saúde (SUS) brasileiro e o desenvolvimento de oficinas de capacitação para informação, pesquisa e comunicação. Ao testar a aplicabilidade da proposta em um espaço de atuação profissional mais aberto, onde se fazem presentes relações de comunicação informais, com um foco centrado nos conteúdos da saúde coletiva, o grupo de pesquisa observa agora a atuação do Agente Comunitário de Saúde (ACS), profissional de base e principal mediador no Programa Saúde da Família (PSF) do SUS. A hipótese se fundamenta na seguinte proposição: uma vez capacitados por especialistas das áreas de informação e comunicação, os ACS poderão atuar como mediadores com uma visão mais ampla em termos comunicacionais. O estudo pretende, também, identificar as fontes de informação utilizadas pelos ACS e as perspectivas de ampliação dessas fontes, depois da capacitação com as oficinas de ALFIN. No processo de transferência de informação, eles terão possibilidades de atuação mais diversificada. Em contrapartida, os conteúdos produzidos nas oficinas também serão objeto de estudo e de ampliação teórica, prática e metodológica do conceito de comunicação extensiva.

Palavras-chave: Comunicação Extensiva, Inclusão Digital Alfabetização em Informação, Transferência de Informação; Objetos de Aprendizagem; Agentes Comunitários de Saúde; Interatividade, hipertextualidade; Hipermidiação; Oficinas de Comunicação e Informação; modelo Todos-Todos.

Abstract: This article presents methodology based on the extensive communication model (SIMEÃO, 2006) and Alfin, an acronym published by Unesco to offer a concept for the process of information literacy acquisition (information literacy), in research applied to the communication context of information on health in Brazil. This paper assesses the mediation of Community Health Agents (ACS) in their work in the Brazilian Unified Health System (SUS) through the development of Alfin training workshops. In testing whether the proposal is applicable in a professional workspace which is more open, with more informal communication relationships, the research group observes the Community Health Agent (ACS), a supporting professional and the main mediator in the Family Health Care Program, and his/her performance as a communicator. The hypothesis is based on the following proposition: once trained by specialists in the fields of technology, information and communication, the ACS will be able to 
act as mediators with a broader view in terms of communication. The study also aims to identify the sources of information used by the ACS and the perspectives of expanding such sources after training in the Alfin workshops. The content produced in the workshops will also be a subject of study and of theory and methodology discussions; this contributes to broadening the proposition of the extensive communication model.

Key words: extensive communication; information literacy; mediation; subjects of learning; community health agents.

Resumen: Hay una literatura emergente en la ciencia de la información que trata dos mecanismos y procesos de alfabetización de la información (informationliteracy), o ALFIN, siglas que fueron divulgadas por la UNESCO y que ya fueron aceptadas por la comunidad científica que estudia el asunto. En este artículo se presenta una metodología amparada en el modelo de comunicación extensiva (Simeão, 2005) para trazar nuevos horizontes para ALFIN en una investigación aplicada al contexto de la comunicación de la información en la sanidad en Brasil. El trabajo evalúa la mediación de los agentes comunitarios de sanidad en su actuación en el Sistema Único de Sanidad (Sistema Único de Saúde, SUS) brasileño y el desenvolvimiento de los cursos de capacitación para la información, investigación y comunicación. Al atestiguar la aplicabilidad de la propuesta en un espacio de actuación profesional más abierto, donde se hacen presentes las relaciones de comunicación informales, como un foco centrado en los contenidos de la sanidad colectiva, el grupo de investigación observa ahora la actuación del Agente Comunitario de la sanidad (Agente Comunitário de Saúde, ACS), profesional de la base y principal mediador en el Programa de la Salud de la Familia (Programa Saúde da Família, PSF) del SUS. La hipótesis se fundamenta en la siguiente proposición: una vez capacitados por especialistas de las áreas de información y comunicación, los ACS podrán actuar como mediadores con una visión más amplia en términos comunicacionales. El estudio pretende, también, identificar las fuentes de información utilizadas por los ACS y las perspectivas de la ampliación de esas fuentes, después de la capacitación con los cursos ALFIN. En el proceso de transferencia de información, ellos tienen posibilidades de actuación más diversificadas. En compensación, los contenidos producidos en las oficinas también serán objeto de estudio y de ampliación teórica, práctica y metodológica del concepto de comunicación extensiva.

Palabras claves: comunicación extensiva; Inclusión Digital Alfabetización Informacional, transferencia de información, objetos de aprendizaje, Agente Comunitario de la sanidad; hipertextualidad; interactividad; hipermediation; talleres de Comunicación e Información; modelo todo-Todo. 


\section{Sobre a Comunicação Extensiva}

Para consolidar o conceito de comunicação extensiva e verificar a pertinência dos indicadores propostos no modelo para comunicação da informação em saúde é preciso dimensioná-los em um ambiente de comunicação mais informal. A idéia não é reduzir a aplicação dos indicadores a uma observação de produtos estruturados, como foi feito nas primeiras investigações do modelo em um ambiente de comunicação científica. Pretende-se agora ampliar seu uso para produtos e serviços de informação de forma estratégica. Parte-se do pressuposto que a informação pode ser construída com base na abordagem conceitual dinamizando ações de projetos e programas com metas específicas, no caso atuando em ambiente de trabalho e educação em saúde coletiva.

O movimento de integração das disciplinas é próprio da ciência moderna. É fortemente amparado pelos recursos tecnológicos de comunicação com uma demanda por produtos e serviços de informação de caráter mais informal. Trata-se de um paradigma de comunicação com ações de mediação integradas por meio dos sistemas eletrônicos mais abertos.

Esse cenário de integração de redes em um espaço global de atuação, ou pelo menos sua possibilidade, não é discussão recente. Já foi previsto por vários autores visionários, como Vannevar Bush e Marshal McLuhan. O teórico dos meios de comunicação de massa e precursor dos estudos midiológicos, por exemplo, prenunciou a chegada da aldeia global que atestamos hoje com a Internet. $O$ interesse de McLuhan não se limitou aos efeitos ideológicos dos meios de comunicação, mas à sua interferência e interação com as sensações humanas. "Meios de comunicação como extensões do homem", título de sua tese mais conhecida, ou "prótese técnica", são expressões do autor para assinalar a influência dos meios de comunicação na percepção e mediação. Já Vannevar Bush, engenheiro e cientista americano, destacou-se por seu trabalho em computação analógica. A idéia do Memex (Memory Extension) - visto como um conceito pioneiro da World Wide Web, parecia antecipar a possibilidade das operações de hipertexto integrando o conhecimento humano.

\section{Origens do conceito de Comunicação Extensiva}

Verificando-se a relação entre expansão tecnológica e integração dos saberes da ciência atual, buscou-se no trabalho do professor e diretor do Centro de Pesquisas Históricas na Ecole des Hautes Etudes em Ciências Sociais, na França, Roger Chartier, e de outros pesquisadores, uma explicação consistente para esse movimento global, aportando-se a uma referência histórica para a tese sobre Comunicação Extensiva (Simeão e Miranda, 2003). A 
obra de Chartier concentra-se na importância da leitura na Europa moderna, explorando a relação entre o texto e o leitor em um cenário marcado pela evolução permanente dos instrumentos de tecnologia de comunicação e mediação. Em "Práticas da leitura" (Chartier, 1996), obra organizada por Chartier com a colaboração de Guglielmo Cavallo, Pierre Bourdieu, François Bresson, Robert Darnton, Daniel Fabre, Jean-Marie Goulemot, Jean Hébrard, Louis Marin e Daniel Roche, estudiosos de disciplinas diversas tentam elucidar os modelos e efeitos, a história e a situação contemporânea de uma prática cultural que é a base de sustentação de todo conhecimento humano, a leitura.

A Leitura é compreendida como um ato que surge da mediação, ato de decifrar signos que traduzem uma linguagem. Não se trata apenas de entender (ler) o mundo pelo prisma de um autor (ou autores), mas também captar essa linguagem que se expressa através de signos (em registros) e que pode tornar fluida a ação comunicativa. Leitura também como processo dinâmico de aprendizagem, de mediação construída pela definição de padrões e códigos, e, ainda, conforme aponta Chartier, uma relação íntima que se estabelece, muitas vezes, entre o leitor solitário e o livro (espaço aberto para a imaginação), entre leitores e seu jornal diário (com suas modernas versões on-line). Essa intimidade do leitor agora integra um espaço de "convivência virtual" onde os internautas e seus pares compartilham experiências e saberes para além dos espaços convencionais.

Ao observar mudanças nas formas de apropriação da leitura na Alemanha no século XVIII e Inglaterra no século XIX, Chartier (1996) constata a passagem de uma leitura "intensiva" para uma leitura que chama de "extensiva", inferindo, dessa maneira, que a absorção de conteúdos pode ser feita por meio de duas formas distintas de apropriação. $\mathrm{Na}$ primeira, afirma o autor, há certo tradicionalismo que impõe regras à leitura e normas para os escritos. O leitor é confrontado com um número restrito de possibilidades que perpetuam os mesmos textos e os mesmos formatos, fornecendo sempre referências idênticas, e assim os conteúdos são mais reconhecidos do que lidos. Essa forma de leitura provoca intimidade com o leitor , é também o cenário das relações mais convencionais e tradicionais de comunicação.

Entre 1750 e 1850, o historiador detecta uma nova maneira de ler que vai, aos poucos e de diferentes maneiras, se impor diante das práticas tradicionais de comunicação (mais intensivas). É um conjunto de práticas que estimula uma leitura mais superficial dos escritos, que traduz também menor investimento na produção dos livros e no capricho com sua ornamentação. Induz à produção de inúmeros exemplares, lidos individualmente de forma descartável, reproduzindo-os intensamente e facilitando sua disseminação e popularização. Essa expansão foi acompanhada do avanço da indústria editorial e trouxe a possibilidade de acessos mais amplos ao conhecimento humano e a sua reprodução em larga escala. Essa ação 
extensiva busca sim um repertório de múltiplos documentos e se aplica a um maior número de pessoas, amplia as formas de mediação e ultrapassa as referências tradicionais de cada área. Mas também promove a leitura em outros suportes, disseminando idéias e captando movimentos numa troca permanente de conteúdos e formas que reproduzem interesses de comunidades interpretantes.

\section{Comunicação extensiva e seus indicadores: interatividade, hipertextualidade e hipermediação}

A partir da definição de três indicadores principais (interatividade, hipertextualidade e hipermidiação) foi possível avaliar aspectos comuns e particulares dos formatos de documentos na web e posteriormente criar uma forma de análise e verificação do modelo de comunicação extensiva. Para explicar pontualmente as possibilidades de identificação de processos extensivos de comunicação, e também testar a implantação de projetos baseados nesse modelo, foi incluído um quarto indicador, o contexto.

Quadro 1- Comunicação extensiva e intensiva (quadro comparativo)

\begin{tabular}{|l|l|}
\hline COM. INTENSIVA & COM. EXTENSIVA \\
\hline Tradicionalismo & Informalidade \\
\hline Normas rígidas & Regras flexíveis \\
\hline Restrições à leitura e edição & Leitura expandida, edição \\
\hline Promove o reconhecimento & interativa \\
\hline Referências idênticas & Promove o inédito, o \\
\hline Leitura lenta, íntima. & inesperado \\
\hline Configuração vertical & Referências diferentes \\
& Leitura rápida e superficial \\
& Configuração horizontal \\
\hline
\end{tabular}

Fonte: Simeão, 2006.

Os indicadores foram construídos em função das principais características apresentadas no conceito de comunicação extensiva, ou seja, deveriam promover a informalidade, uso de regras flexíveis, leitura expandida, edição interativa. Estímulo ao uso de 
referências diferentes, do conteúdo inédito, com formatos que induzem à leitura rápida e superficial, com uma configuração horizontal e aberta à participação de vários grupos, com a formação de redes.

A interatividade, a hipertextualidade e a hipermidiação são os indicadores de formato de informação que servem para identificar em que nível de implementação os produtos e serviços de informação alcançariam uma perspectiva de uma ação mais extensiva. O primeiro indicador estaria mais vinculado aos produtos e serviços que incluem os usuários e grupos de pessoas, os dois seguintes estariam ligados a prática de formatação e interpretação dos conteúdos. Todos eles precisam da "análise contextual complementar" (quarto indicador), pois esse método pode ser aplicado tanto para analisar produtos e serviços de informação, como para oferecer uma política com tal motivação.

A interatividade é compreendida como a possibilidade de diálogo entre o usuário (interpretante) e o sistema de informação. Explica e pontua a relação de usuários entre si, através do sistema, com ferramentas que promovem um contato temporário ou permanente entre grupos, procurando sua aproximação e integração. Pode contemplar também conteúdos sobre o sistema e a sua utilização, seus produtos e serviços, visando o atendimento ao público. A principal característica desse indicador é a interação do sistema com seus usuários, sejam eles emissores ou receptores. Da perspectiva complexa, apontada por Morin, retira-se "informação como instrumento de diálogo". A própria regulação se dá pelo diálogo, sendo que "a dialógica permite assumir racionalmente a associação de noções contraditórias para conceber um mesmo fenômeno complexo" (MORIN, 2000, p. 34)., ou seja comporta a idéia de que os antagonismos podem ser estimuladores e reguladores".

Hipertextualidade é o indicador de vínculos entre os diversos conteúdos e as múltiplas combinações transdisciplinares. É demarcado pelos links que se estabelecem entre pessoas por meio das formas integradas de comunicação de conteúdos nos sistemas modernos, notadamente os que usam a lógica operacional do hipertexto (conceitual e não somente de deslocamento). O conceito analisado nesse indicador tenta buscar vínculos não a partir de pessoas, como aponta com mais precisão o indicador de interatividade e, com mais propriedade, o modelo de comunicação "todos-todos" de Mendonça (2007), mas na descoberta de inúmeras possibilidades de conexão entre temáticas distintas.

Há sempre a possibilidade de uma afinidade entre discursos de áreas distintas. A tematização dos conteúdos aportada durante a mediação pode determinar os possíveis pontos de integração das disciplinas. Morin usa o mesmo raciocínio ao avaliar a informação como instrumento de complexidade, destaca a necessidade de um método que reúna o separado, afronte o incerto e supere as insuficiências lógicas: 
(...) O que tentamos e acreditamos encontrar, foi este lugar de cruzamento para as pesquisas fundamentais, um conjunto teórico/metodológico/epistemológico, ao mesmo tempo coerente e aberto. (MORIN, 2007, p.49)

Para o autor a ciência (scienza nuova) não poderia se prender à conceitos, mas criar um caminho entre eles, garantindo que o mundo jamais se aprisione no discurso.

A Hipermidiação é o indicador que identifica nos produtos e serviços de informação a superação das práticas convencionais de diálogo. É a combinação da informação em suas múltiplas dimensões: texto, imagem e áudio são utilizados na construção do conteúdo numa lógica discursiva não linear que obedece aos comandos de criação do usuário, com recursos múltiplos. Mesmo sem limites (nas temáticas) há de se respeitar a permanência do diálogo e de sua crescente possibilidade de expansão. Neste momento, resgata-se a preocupação estética, cuja perfeição consiste na construção dialógica em formatos harmônicos, como nas expressões artísticas, buscando a perfeição das formas que mantém o equilíbrio no diálogo. A hipermidiação distingue-se dos indicadores anteriores, por concentrar-se na capacidade de promover a construção de conteúdos em bases metatextuais e multidimensionais.

Defende-se que a combinação das três características da comunicação extensiva cria um mecanismo que rompe com o modelo tradicional de comunicação das publicações e da organização de acervos em sistemas de informação. Diante da ação comunicativa extensiva caberá às ciências da informação entender os conflitos na comunicação de emissores e receptores. O trabalho contínuo de produção, organização, recuperação e formatação de discursos na web levará seus interpretantes a novas regras, que também não podem ser vistas como produto acabado, ou obra pronta.

A comunicação extensiva é um processo que avança com a instrumentalização de sistemas abertos, cooperativos e de compartilhamento de dados. É uma mediação com fluxo horizontal que tem como objetivo a solução de um problema que atinge comunidades interpretantes e produtoras de conteúdos com uma forte influência dos aparatos técnicos. É a comunicação sem regras pré-definidas, sem um padrão fixo, sem fronteiras. É a interação de emissores e receptores com uma lógica hipertextual, pontual e objetiva em suas metas, mas efêmera, sem estoques e em constante mutação. Pontual e precisa é também uma mediação transitória. É um entrelaçamento de pessoas e de idéias em sistemas complexos que tentam responder sincronicamente às demandas de seus usuários, tem um padrão de informação 
qualitativamente diferente e dependente operacional da tecnologia da computadorização (DIZARD, 2000).

O computador e as redes virtuais tornam-se instrumentos usuais de mediação: são rápidos, permitem a troca de um grande volume de dados em uma escala global e local. A tecnologia de comunicação atualmente é o módulo para quase todas as formas de mediação e produção dos documentos (convencionais ou não) que se imbricam no espaço comum de uma rede global integrando som, imagens e textos. $O$ modelo de comunicação extensiva poderia ser facilmente representado como uma rede de conexões e mediações autônomas, mas interligadas, prenunciando o fim das hierarquias e o início de uma ordem informacional que tem como paradigma o espaço livre da negociação e a liberdade de expressão, com diversidade de fazeres e métodos para a mediação.

A formulação que sustenta o conceito de mediação e comunicação extensiva não se apóia totalmente na tecnologia, ou seria inócua. Ao apresentar a nova literatura do século XXI no livro "Seis propostas para o próximo milênio" Calvino traz um resumo preciso das características mais importantes do texto, que independente da tecnologia garantem o entendimento e a "comunhão de idéias". Essas qualidades, em diferentes formas de expressão, demonstram acurácia e técnica de escritura. É o texto (compreendido em um sentido mais amplo) que determina o ritmo da narrativa e sua compreensão. Há também variáveis relacionadas ao contexto social, cultural e político.

Para que se entenda ou ainda, que se discuta mediação como processo de comunicação, é importante observar os códigos culturais daquela sociedade. Os pólos envolvidos no processo de transferência de informação alternam os seus papéis durante a interlocução. Assim sendo, receptores e emissores assumem a posição de mediador de acordo com o tempo e o espaço, à medida em que se processam as forças de conflito. Esta complexidade se acentua com as diferenças culturais, e seus códigos, daí a necessidade da figura do mediador, como agente social transformador ativo, que assegura que o conteúdo de uma informação seja traduzido e possa produzir conhecimento num espaço comunicacional.

A mediação assume assim um caráter conciliador, e de equilíbrio de condutas no espaço informacional. Como ação intermediária, a mediação é capaz de intervir para transformar um contexto discursivo (possivelmente conflituoso), em um estágio dialógico conformador, encontrando assim um termo conciliador. Nesse contexto o discurso mediado se transforma em uma negociação de interesses.

\section{O ACS como mediador estratégico do SUS}


Em todo o país são cerca de 204 mil ACS, estando presentes tanto em comunidades rurais e periferias urbanas quanto em municípios altamente urbanizados e industrializados, integrados ao programa "Saúde da Família", coordenado pelo Ministério da Saúde. Os ACS são essenciais nas funções de informar e comunicar sobre saúde no Brasil. Possuem os mesmos signos e símbolos considerados essenciais no ato de mediar, possibilitando uma identificação mais rápida e um relacionamento mais dinâmico, de trocas, em que o cidadão pode se identificar por meio da linguagem comum, estabelecendo uma relação baseada na confiança, substantivo essencial quando a temática é saúde. No modelo de comunicação extensiva o processo de mediação pode ser ampliado pois permite a construção e uso coletivos de linguagens comuns e cada vez mais complexas como citado anteriormente. Os conteúdos são resultado de edições compartilhadas.

É importante que o ato de comunicar seja transformador tanto naquele que comunica quanto no comunicado, uma vez que as expressões "não podem nascer completamente formadas, têm que desenvolver gradualmente"; os complexos processos mentais de significação também têm que se desenvolver e aperfeiçoar (VYGOTSKY, 19??, p. 89). As novas comunidades virtuais são formadas por interesses temáticos e a sociedade da informação. Nesse contexto, os suportes evoluem para conectarem informações em diversos níveis, criando redes de diferentes proporções, com um crescente número de usuários e comunidades.

As dificuldades quanto à compreensão das possibilidades de comunicação também são evidentes quando se observa que não há preocupações quanto à formação de um comunicador durante os treinamentos do ACS. Neste artigo, a visão da saúde coletiva é incluída como uma alternativa paradigmática das ciências da saúde tradicionais, que focam na doença e seus diagnósticos. Os serviços de saúde no Brasil são organizados no e pelo SUS, oriundo e representante do processo de redemocratização do estado brasileiro na década de oitenta. Este sistema de saúde, em uma de suas diretrizes, aborda o desmonopólio do conhecimento como estratégia de transferência de informação, onde o profissional da área transmite seus conhecimentos à comunidade usuária dos serviços. Apesar disso, diversos vieses dificultam este processo, como o nível de conhecimento a ser transferido e a capacidade de absorção do produto pelo receptor.

Considerando a estratégia do PSF' que inclui um conjunto de ações voltadas à promoção, à proteção e à recuperação da saúde, garantindo os princípios da universalidade, e da integralidade e da eqüidade, é indiscutível o papel de comunicador que os profissionais possuem e a necessidade permanente de avaliação de instrumentos e de processos que podem aferir resultados mais promissores no cenário da saúde brasileira. 
Conforme critérios do PSF para admissão profissional, todo agente comunitário de saúde deverá trabalhar na mesma comunidade onde mora, o que confere ao ACS conhecimento efetivo (simétrico) daquela localidade, e uma natural intimidade com os problemas e com a rotina do lugar de moradia. Compreender-se como comunicador, como um sujeito que educa e transforma por meio das informações que dissemina é fundamental para o trabalho motivado dos agentes. Uma vez capacitado por especialistas das áreas de informação e comunicação, poderá atuar plenamente como mediador no processo de transferência de informação, já que detém a experiência da convivência e de prováveis boas práticas com a comunidade.

O Brasil é um país de extremos. Pressupõe-se que com a capacitação em comunicação e informação em saúde, o processo de transferência de informação torna-se pertinente e relevante, uma vez que o conhecimento sobre temas referentes à saúde coletiva, pode chegar a todos os usuários do SUS, sem distinção, observando um dos princípios deste sistema que é a universalização dos seus procedimentos.

Durante seu treinamento permanente, o ACS entra em contato com modelos convencionais de comunicação atuando como receptor, em que, neste momento, ele (o ACS) e o instrutor consolidam o processo de aprendizagem de determinado tema ou informação por meio de capacitação, utilizando, ou não, instrumentos, ou objetos de aprendizagem.

Após o processo de aprendizagem, o ACS se torna receptor e emissor daquele conteúdo, e, na sua atuação com a comunidade, age como mediador. A partir disto, a comunidade se torna um pólo receptor e emissor para o ACS, que promove a disseminação de conhecimentos e retorna para o SUS o conteúdo daquela comunidade, fechando um circuito comunicacional.

\section{Rompendo barreiras e ampliando o modelo}

Os projetos de Inclusão Digital realizados em Sergipe e no Distrito Federal foram iniciados em 2007 por meio de oficinas e seminários preparatórios, culminando com a realização de dois grandes eventos internacionais" que envolveram especialistas das áreas de informação, comunicação e saúde coletiva, incluindo os ACS. Foi necessário incluir na proposta a participação de estudantes de iniciação científica (inicialmente da área de biblioteconomia), para a montagem dos primeiros guias de fontes de informação do projeto. As oficinas para Informar, Educar e Comunicar em Saúde foram desenvolvidas e monitoradas por professores e alunos do Programa de Pós-Graduação em Ciência da Informação, da Universidade de Brasília, e também do Núcleo de Estudos em Saúde Pública. De acordo com a proposta, apresentada posteriormente ao Ministério da Saúde em pedido formal de financiamento: 
O projeto foi desenhado de forma participativa entre a coordenação geral e os demais membros que compõem a equipe de execução, levando em consideração:

a) A demanda social da pesquisa no que se refere à importância da inclusão digital dos ACS para a qualificação de suas práticas no cotidiano do seu trabalho, tendo centralidade, a informação, a educação e a comunicação em saúde;

b) A integração entre o ensino, a pesquisa e a extensão, tendo as comunidades como sujeitos ativos da ação-reflexão-ação, de suas condições de vida e saúde;

c) A possibilidade do uso de ferramentas em software livre, a fim de proporcionar o diálogo entre esta tecnologia junto aos pesquisadores de outras Instituições de Ensino e Pesquisa, como forma de articulação e troca de experiências no desenho dos métodos e conteúdos e modelos aplicados à avaliação do projeto.

Na elaboração, foram avaliados os desafios contemporâneos à formação dos ACS tendo a política de inclusão digital como uma oportunidade ao aperfeiçoamento do seu trabalho, considerando não somente aspectos relacionados à tecnologia, mas principalmente o potencial de um aprimoramento comunicacional.

Para operacionalizar a proposta no Programa de Pós-graduação em Ciência da Informação da Universidade de Brasília, criou-se um grupo de pesquisa com o foco direcionado às disciplinas da comunicação, informação e saúde coletiva, com forte influência dos estudos tradicionais de IEC (Informação, Educação e Comunicação), cujo lastro teórico no Brasil se fundamenta nas proposições do educador Paulo Freire. O objetivo do grupo, que envolve alunos e pesquisadores de áreas distintas é atuar com equipes do Programa Saúde da família (PSF) e promover a produção de conteúdos com base nos indicadores de comunicação extensiva e de ALFIN. A mediação é pontuada por oficinas de aperfeiçoamento para o uso de tecnologias de comunicação.

As oficinas têm o apoio de monitores e alunos de Iniciação Científica, voltado para a capacitação do ACS no Distrito Federal. As equipes são coordenados pelo Núcleo de Estudos em Saúde Pública (NESP) e Departamento de Ciência da Informação e Documentação (CID), ambos da Universidade de Brasília. O material didático foi selecionado com base nas características e atribuições previstas para a competência leitora e aperfeiçoamento e estímulos para alfabetização informacional (ALFIN).

Além dos ACS no Distrito Federal e entorno o projeto tem por finalidade avaliar os projetos de inclusão digital dos Agentes Comunitários de Saúde do estado de Sergipe e, no período de 2008 a 2013, no que se refere à produção de conteúdos, a recepção, a mediação e 
a aplicabilidade social, sustentado pela integração dos campos da Informação, Educação e Comunicação.

Para esta investigação também são considerados objetos de estudos os multiplicadores, alunos de graduação, representantes das comunidades e gestores envolvidos direta ou indiretamente nos projetos, identificados como mediadores. A seleção dos representantes das comunidades ocorrerá mediante abordagem casual (aleatória), na oportunidade da visita dos ACS. Quanto aos gestores, os mesmos serão entrevistados em um segundo momento, segundo a relevância institucional de sua função nos sistemas municipal e ou estadual de saúde nos territórios de desenvolvimento do projeto. Os dados serão oriundos de diferentes fontes: documentos, observação direta do contexto e entrevistas.

\section{Pesquisa com ALFIN}

Entre os conceitos mais comuns de ALFIN destacam-se aqueles que reforçam o trabalho de "ensino e aprendizagem" para o desenvolvimento de conhecimentos e habilidades em pesquisa. Dessa forma a didática se apoiaria em atividades de procura e aplicação de informação, com a identificação de tipologias e percepção de necessidades informacionais. A decisão de implementar um programa de ALFIN, associado ao trabalho do ACS, é um tentativa estratégica de melhorar a condição de atendimento de um setor sensível, que possui um grande acervo materiais especializados, mas que peca por não tratar de forma adequada as informações educativas com linguagens mais populares e acessíveis. Não há políticas com a preocupação de qualificar melhor os profissionais do PSF nesse sentido. São os ACS os comunicadores em potencial que entendem e convivem com a realidade das comunidades nas áreas urbanas e rurais, por isso a escolha desse ator no estudo proposto.

É importante destacar que o projeto trabalha tanto a capacitação individual, quanto as habilidades coletivas nos processos de comunicação. $O$ uso da internet é freqüente nas oficinas de trabalho, pois por meio das pesquisas por temas. O ACS aprende a criar critérios de seleção e também de organização da informação. No início do trabalho nas oficinas toda uma base conceitual sobre informação é discutida e apresentada como uma ferramenta para a solução de problemas cotidianos. Em vários países a biblioteca pública e também a biblioteca escolar servem de apoio para o desenvolvimento das oficinas. No Brasil isso é problemático já que essa tipo de instituição não recebe incentivos e investimentos para assumir integralmente o papel de promotora da alfabetização informacional

Entre as instituições que se destacam internacionalmente na divulgação de ALFIN, a International Federation of Library Associations (IFLA) tem realizado importante trabalho de compilação das experiências. As normas da IFLA estão baseadas nas experiências de vários 
países e podem ser agrupadas em três componentes básicos: acesso, avaliação e uso da informação.

O acesso se caracteriza pela definição e caracterização da necessidade informativa, e da decisão pela busca e localização da informação. Na avaliação, o usuários estabelecem critérios de forma crítica, analisam e interpretam os resultados de uma busca ( pesquisa) e são capazes de estabelecer prioridades, ordenando e classificando os dados. No uso desenvolvemse atividades de comunicação e produção de conhecimento. Em muitas experiências, nas atividades de capacitação para ALFIN são incluídos aspectos éticos sobre o uso da informação. No caso do projeto de pesquisa desenvolvido com os ACS optou-se pelas seguintes etapas:

a) Inclusão digital (aprendizagem sobre hardware e softwares, priorizando o uso de software livre;

b) Conhecendo a informação objetiva

c) Aprendendo a pesquisar

d) Descobrindo a comunicação

e) Modelo Extensivo

f) Modelo colaborativo, Todos-Todos.

g) Discutindo a ética e os direitos humanos

A pesquisa teve início com um estudo envolvendo a identificação de guias de fontes de informação na área de saúde coletiva, e na elaboração de materiais para estimular a capacitação para a leitura e pesquisa, considerando diferentes tipos de informação e habilidades para o uso de tecnologias de informação. Parte das dinâmicas adotadas foi adaptada a partir de propostas e práticas realizadas por outros programas de capacitação desenvolvidos em São Paulo. Um exemplo importante é o estudo com alunos do ensino fundamental do Brasil durante atividades desenvolvidas e criadas pelo Grupo de Referência em Informática Educativa (SME-SP) com a mediação das equipes do DOT Ensino Fundamental e Médio - Informática Educativa e do Programa EducaRede, em trabalho semipresencial, divulgado amplamente na internet.

Mujica et AL (2008), consideram competência como a posse de qualificações intelectuais, físicas e condutas suficientes (conhecimentos, habilidades e atitudes) para realizar uma tarefa o desempenhar um papel de maneira adequada para alcançar um resultado desejado.

A Associação Biblioteca Médica extende o conceito de alfabetização informacional no campo da saúde, e a define como o conjunto de habilidades necessárias para reconhecer uma necessidade de informação em saúde, identificar fontes de informação adequadas e utilizá-las para recuperar informação relevante, avaliar a qualidade da informação e sua aplicabilidade 
para uma situação específica, assim como analisar, compreender e empregar esta informação para tomada de decisões adequadas em saúde (BAWDEN, 2008). É necessário portanto dispor de um documento que defina as competências informacionais como parte de um sistema de normas para o ambiente das bibibliotecas de saúde (MUJICA et $A L, 2008$ ). A necessidade de desenvolver competências específicas para a área de saúde é assim vista por Espinet:

...se se tem bem definido a natureza das habilidades informacionais como uma competência de caráter transversal, alguns autores afirmam que tais habilidades, a pesar de poderem ser transferíveis, se aprendem e interiorizam melhor associadas com um contexto e uma área determinada; nesse sentido, as peculiaridades de cada disciplina reclamam a existência e o desenvolvimento de modelos específicos para a formação de competências em informação... No âmbito das ciências da saúde, o acesso e utilização da informação adquire especial relevãncia na prática profissional. É por isto que se contempla o desenvolvimento de habilidades como competências específicas e básicas para o desenvolvimento profissional. (ESPINET, 2008)

Para atingir os objetivos propostos no projeto de Inclusão e ALFIN no DF, as dinâmicas e atividades foram adaptadas considerando o perfil profissional e a função do profissional no contexto do PSF, que tem como missão promover ações preventivas e de educação para promoção da saúde coletiva no Brasil. É importante durante o desenvolvimento das oficinas observar o movimento de aprendizagem que envolve tanto os ACS, público-alvo da proposta de ALFIN, quanto os alunos de graduação e pós-graduação que realizam pesquisas na área de informação e saúde. São universitários dos cursos de graduação em Biblioteconomia, Saúde Coletiva, Arquivologia, Computação e também pós-graduandos em Saúde Coletiva e Ciência da Informação.

A atividade é complementada com uma permanente avaliação das ações e a disseminação de produtos e serviços, como livros, apostilas, guias de fontes, artigos científicos, etc. As dinâmicas incluem tanto habilidades com o uso de equipamentos e softwares, quanto no letramento digital e competências leitoras, de pesquisa e de comunicação.

Ao ACS são capacitados para uma comunicação colaborativa, integrando as habilidades desenvolvidas para um ambiente de comunicação extensiva, ou seja, com recursos múltiplos e informação multidimensional. É importante destacar que independente dos formatos, os conteúdos devem estar integrados às suas funções e conhecimentos com profissionais de saúde pública. Nas oficinas eles também devem produzir materiais com planejamento 
estratégico (com metas, discutido em equipe) visando a realização de campanhas e ações integradas.

Em sua construção metodológica o PIC tenta indicar caminhos para pesquisas que poderão subsidiar ações de apoio aos projetos de inclusão digital do conjunto de municípios brasileiros que atuam com os ACS, no que se refere a educação permanente desses profissionais por meio eletrônico e presencial (uso de tecnologias avançadas). A inclusão digital dos ACS representa um acompanhamento dos avanços tecnológicos que podem aprimorar o processo de conhecimento à distância ou semipresencial destes profissionais, além de possibilitar às comunidades atendidas por estes Agentes, o acesso à informação, à educação e à comunicação nas questões de saúde publica, auxiliando-as nos processos de educação e uso da informação como bem público.

\section{REFERÊNCIAS}

BRASIL. Ministério da Educação; Ministério da Saúde. Referencial curricular para curso técnico de agente comunitário de saúde: área profissional saúde. Brasília: Ministério da Saúde, 2004. $64 \mathrm{p}$.

BUSH, Vannevar. As we may think: the growth of knowledge. Readings on Organization and Retrieval of Information. Atlantic Monthly, 176, n.1, julho, 1945, p. 101-108. Disponível em: http://www.theatlantic.com/unbound/flashbks/computer/bushf.htm.

CAVALLO, Guglielmo; CHARTIER, Roger (Orgs.). História da leitura no mundo ocidental. São Paulo: Ática, 1998. (Múltiplas escritas,L v. 1-2).

(Org.). Práticas da leitura. Tradução de Cristiane Nascimento. São Paulo: Estação

Liberdade, 1996.

DIZARD, Wilson. A nova mídia: a comunicação de massa na era da informação. Tradução de Edmond Jorge. 2. ed. Rio de Janeiro: Jorge Zahar, 2000.

MASUDA, Y. A Sociedade da Informação como sociedade pós-industrial. Rio de Janeiro: Editora Rio, 1980.

MENDONÇA, A. V. M.. Informação e Comunicação para Inclusão Digital. 1. ed. Brasília: Editora do Departamento de Ciência da Informação e Documentação da Universidade de Bra-sília, 2008.

A Integração de Redes Sociais e Tecnológicas: Análise do Processo de Comunicação para Inclusão Digital. Tese [Doutorado]. Programa de Pós-Graduação em Ciência da Informação. Departamento de Ciência da Informação. Universidade de Brasília. Brasí-lia, 2007. 
LATOUR, Bruno. Redes que a razão desconhece. Tradução em prefácio in PARENTE, André (Org.). Tramas da rede. Porto Alegre: Sulina, 2004. p. 39-63.

McLUHAN, M. Os meios de comunicação como extensão do homem: understanding media. Tradução de Décio Pignatari. São Paulo: Cultrix, 1971.

MIRANDA, Antonio ; SIMEÃO, Elmira. A conceituação de massa documental e o ciclo de interação entre tecnologia e o registro do conhecimento. DataGramazero. Disponível em: http://, http://www.dgzero.org/dez02/F_I_dgz.htm 2002. Acesso em: dez. 2002.

MIRANDA, Antonio; SIMEÃO, Elmira (Org.). Alfabetização digital e acesso ao conhecimento. Brasília: Universidade de Brasília, 2006. 257 p. Série Comunicação da Informação Digital, n. 4.

MORIN, Edgar. Da necessidade de um pensamento complexo. IN: MARTINS, Francisco Menezes e SILVA, Juremir Machado da. Para navegar no século XXI: tecnologias do imaginário e cibercultura. 2. ed. Porto Alegre, Sulina/ EDIPUCRS, 2002.

MORIN, Edgar. A cabeça bem-feita: repensar a reforma, reformar o pensamento. 8 a ed. Rio de Janeiro: Bertrand Brasil, 2003

MORIN, Edgar Introdução ao Pensamento Complexo. 3. ed. Porto Alegre, Editora Sulina, 2007.

SIMEÃO, Elmira. Comunicação extensiva e informação em rede. In: Série Comunicação da Informação Digital, vol. 2. Departamento de Ciência da Informação e Documentação Brasília: Unb/CID, 2006.

VYGOTSKY, L. S. Pensamento e linguagem. Disponível em: $<$ http://p.download.uol.com.br/cultvox/livros gratis/pensamento linguagem.pdf $>$.

Notas

' definida por meio da Portaria no. 648/GM, de 28 de março de 2006, que preconiza a coordenação do cuidado a partir da atenção básica organizada pela estratégia Saúde da Família; da Política Nacional de Práticas Integrativas e Complementares - PNPIC no SUS (Portaria no. 971/GM, de 3 de maio de 2006, que regulamenta o desenvolvimento das ações que compreendem o universo de abordagens denominado pela Organização Mundial da Saúde - OMS de Medicina Tradicional e Complementar/ Alternativa) e, principalmente, da Política Nacional de Saúde do Brasil,

"CIACIS (colocar data) e o .... 